\title{
Sound signal of the Himalayan marmot in its insular range
}

\author{
Alexander Nikol'skii", Elena Vanisova, and Konstantin Belovezhets \\ Peoples Friendship University of Russia (RUDN University), Faculty of Ecology, 6 Miklukho- \\ Maklaya Street, Moscow, 117198, Russian Federation
}

\begin{abstract}
The range of Himalayan marmot (Marmota himalayana Hodgson, 1841) has an insular character, as it is limited by ecological and geographical barriers: in the north, northeast and east, these are deserts and the Loess Plateau, in the west - mountain peaks covered with glaciers and rivers, in the south - forests of the southern macro slope of the Himalayas. Only in the northwest of the range there is an ecological corridor. The geographical isolation of populations of marmots provokes the divergence of alarm call, which is one of the obvious genetically determined features. The results of cluster analysis based on a complex of features of the sound signal coincide with the results of analysis using nuclear and mitochondrial DNA. The projection of variability on the structure and history of the landscape contributes to understand the ecological and geographical factors of divergence as the basis for the process of speciation.
\end{abstract}

\section{Introduction}

The range of Himalayan marmot (Marmota himalayana Hodgson, 1841) is a giant "island" surrounded by ecological and geographical barriers limiting its distribution in Central and Western China, where it inhabits the Qinghai-Tibetan Plateau and adjacent areas, including such mountain ranges as Kunlun, Arka Tagh, Altyn Tagh, Nan Shan.

The southern outskirts of the range of Himalayan marmot reach the border of Tibet with the Himalayas in Sikkim, Nepal and Bhutan [1-5].

The species forms two subspecies, M. himalayana himalayana Hodgson, 1841 and $M$. h. robusta Milne-Edwards, 1871 [2, 4], which was recently confirmed by Chinese specialists at the molecular-genetic level [5]. M. h. himalayana is common in southern Tibet, and M. h. robusta - in the provinces of Qinghai, Tibet, in the west of Sichuan, as well as in the provinces of Yunnan, Gansu, and Xinjiang, but the border between the subspecies remains discussable [4].

The southern border of the range of the Himalayan marmot is at the same time the southern border of the range of the genus Marmota, inhabiting the open spaces of mountains and lowland steppes in North America and Eurasia. Due to the high uplift of the Himalayas and at the same time due to location at a relatively low latitude (about $27^{\circ} \mathrm{N}$ ), which raises the border of the snow line, between the upper border of the forest (about 3500

*Corresponding author: bobak@list.ru 
$\mathrm{m}$ above sea level) and a high-rise snow line (up to about $5500 \mathrm{~m}$ above sea level), a space of alpine meadows is formed, suitable for marmots.

In the north and northeast the Himalayan marmot borders on the Mongolian marmot ( $M$. sibirica), in the northwest on the gray marmot (M. baibacina) and in the west on the longtailed marmot (M. caudata) (Fig. 1) [6]. All three species have huge ranges and their proximal to the Himalayan marmot parts are peripheral.

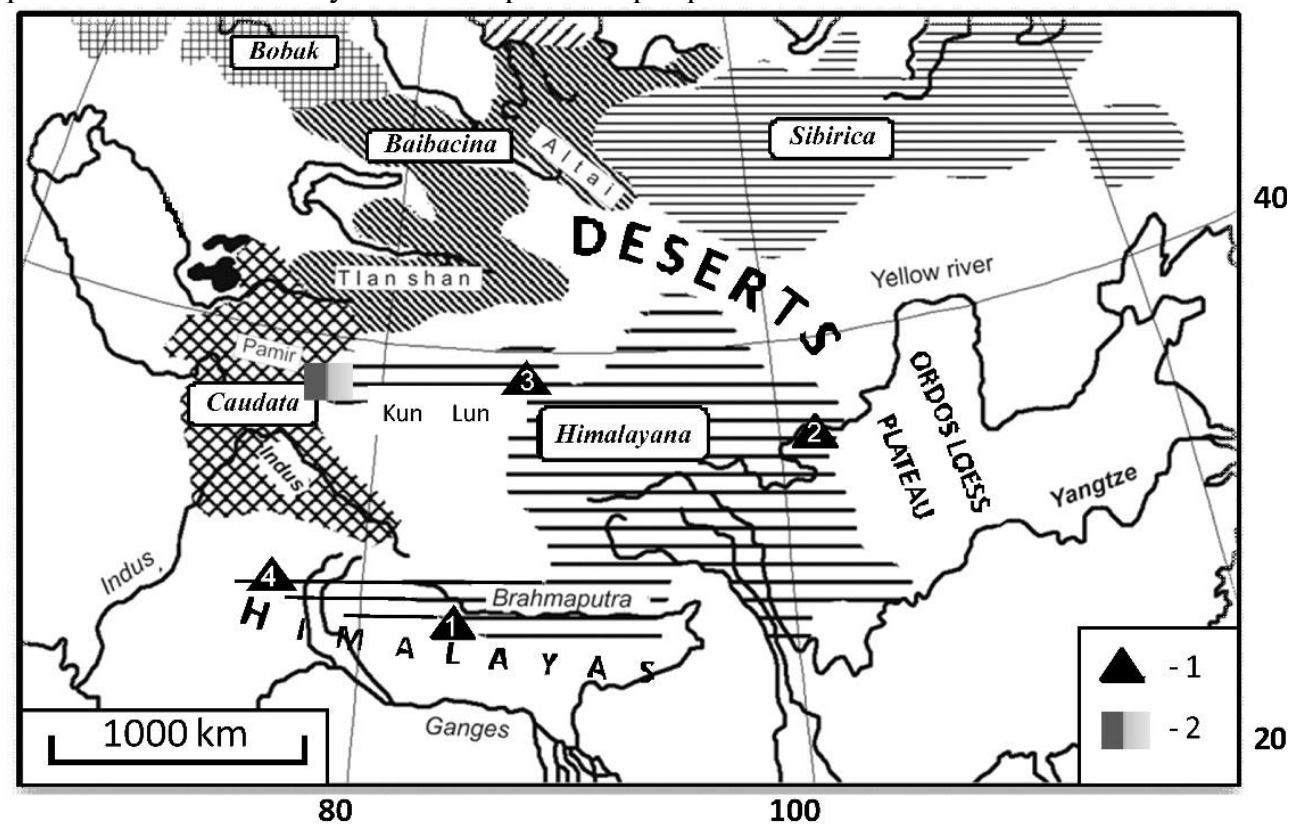

Fig. 1. Distribution of the Himalayan marmot (the base of the map is taken from [6]). 1 - Places of recording of the Himalayan marmot' alarm call, the population numbers are indicated inside the triangles: 1 - "Manaslu", 2 - "Xining", 3 - "Kunlun", 4 - "Sarchu" (3, 4 according to [7], as amended). 2 - Prospective joint settlement of the Himalayan and long-tailed marmots.

Insuperable ecological and geographical barriers separate the range of the Himalayan marmot from the neighbors (Fig. 1). In the north, northeast and east, these are deserts unsuitable for marmots, such as Taklamakan, Gobi, Ala Shan, Ordos, as well as the Loess Plateau. The latter is a good example of an ecological barrier: the structure of the loess doesn't allow marmots to make reliable burrows. It is caused by the property of loess to form vertical faults [8] destroying marmot burrows to a great depth [9].

The expansion of the Himalayan marmot to the west is limited by mountain peaks covered with glaciers and rivers. Its western border is the peaks of Muztagata $(7546 \mathrm{~m})$ and Chicory $(8611 \mathrm{~m})$, which are located on the eastern bank of the upper reaches of the Yarkand River. Both peaks, as well as the Yarkand River, a tributary of the Tarim River, represent a barrier separating the ranges of the Himalayan and long-tailed marmots [3].

In the south, the Himalayan marmot stopped on the southern macro slope of the Himalayas, covered with forests unsuitable for its habitat.

The scale of ecological and geographical barriers is impressive. The plain deserts of Central Asia stretch from west to east for thousands of kilometers. The Tarim Basin includes one of the greatest deserts in the world, the Taklamakan Desert. The deserts of Ala Shan, Gobi, and Ordos are no less grandiose. And of course there is the giant wall of the Himalayas insulating Tibet.

The only place where the insular range of the Himalayan marmot connects with the outside world is in the west of the Tarim Basin. Here the boundaries of its range overlap 
with the boundaries of the range of the long-tailed marmot (Fig. 1). Such an ecological corridor between the Taklamakan, Gobi and Ala Shan deserts in the north and the desert high-mountainous plain of Qaidam, lying at an altitude of 2000-3000 m above sea level between the Altyn Tagh, Nan Shan and Kunlun mountains, is formed by the ridges of the Nan Shan, Altyn Tagh and Arka Tagh passing into one another.

It is quite expected that in conditions of isolation inter specific divergence and species specificity of features is occurred. One of the obvious genetically determined features of marmots is an alarm call [10]. Moreover, it was confirmed that the divergence of the signal characteristics of marmots is provoked by the geographical isolation of populations [11]. The Himalayan marmot is not an exception.

\section{Material and Methods}

To describe the geographical variability of the alarm call of the Himalayan marmot, we use previous publications $[7,12]$. We understand that this material is insufficient for a complete generalization, but nevertheless it gives some idea about the scale of sound signal variability in the range of the Himalayan marmot. Below we list the collection sites and the amount of material. The serial numbers correspond to the numbers of marmot populations (Fig. 1):

1. "Manaslu" - Central Himalayas, Manaslu massif. Nepal, Gandaki Province, Gorkha district, the vicinities of Sama village, valley of the Larke river, $3450 \mathrm{~m}$ above sea level, $\mathrm{N} 28^{\circ} 40^{\prime}, \mathrm{E} 84^{\circ} 40^{\prime}, 2004,18$ exemplars (collected by A.A. Nikol'skii),

2. "Xining" - Northwest Plateau, China, east of Qinghai province to the south-southeast from the capital of province, Xining city, about $3100 \mathrm{~m}$ above sea level, $\mathrm{N} 35^{\circ} 44^{\prime}$; E101 ${ }^{\circ} 56^{\prime}, 2014,8$ exemplars (collected by A.A. Nikol'skii, Wang Chi),

3. "Kunlun" - Middle Kunlun, China, Xinjiang Uyghur Autonomous Region, Qiemo County, 1994: 1) vicinities of Tura village, upper reaches of the Dimnalyk river, right

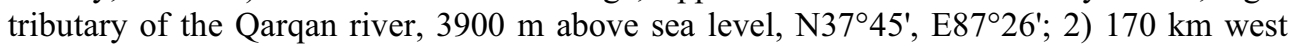
from the Aqqikkol lake, $4200 \mathrm{~m}$ above sea level, N37 $04^{\prime}, \mathrm{E} 86^{\circ} 15^{\prime}, 5$ exemplars (collected by N.A. Formozov). These two points are situated on the slope of the same ridge and there was not found any significant difference in signal structure between them, so we believe it appropriate to combine them.

4. "Sarchu" - Western Himalayas, India, state of Himachal Pradesh, to the north from the Baralacha-la passage, $10 \mathrm{~km}$ south-east from the Sarchu village, about $4900 \mathrm{~m}$ above sea level, N32 $51^{\prime},{\mathrm{E} 77^{\circ}}^{\circ} 1^{\prime} ;$ 2000, 1 exemplar (collected by N.A. Formozov).

\section{Results}

This secondary contact of Himalayan and long-tailed marmots in the west of the Tarim Basin is probably caused by the progress of the Himalayan marmot to the northwest along a favorable ecological corridor. According to oral communication (Liao Lifu) these two species as a result of the secondary contact form joint settlements in which interspecific hybridization is not excluded. The cases of interspecific hybridization were previously shown for pairs of steppe (M. bobak) - gray marmots and Mongolian - gray marmots [13$15]$.

The unique sound signal structure of the Himalayan marmot corresponds to the insular position of its range. This isolation has lasted for millions of years, since the Mongolian plateau was "fenced off" from the Tibetan plateau by a belt of deserts unsuitable for habitation of marmots. 
According to modern concepts the Mongolian plateau was formed as a result of the expansion of the Tibetan plateau to the northeast [16], and the separation of these two plateaus, with the formation of insurmountable barriers, occurred about 5 million years ago. At least the age of the main ecological-geographical barrier, the Taklamakan Desert, is approximately 5.3 million years [17]. Given the process of aridization in the vast Tarim Basin region, which led to the formation of the Taklamakan Desert [17], it can be assumed that the neighboring Gobi, Ala Shan and Ordos deserts were formed at about the same time.

We focus on the processes associated with the formation of the north-northeastern ecological-geographical barrier in the range of the Himalayan marmot, taking in consideration its proximity to the northern neighbor, the Mongolian marmot, which will be discussed in more detail below. These two species probably have a common fate associated with the fate of the Tibetan Plateau and its "derivative" - the Mongolian Plateau.

Fig. 2 shows the characteristic of the alarm call of the Himalayan marmot and neighboring species.
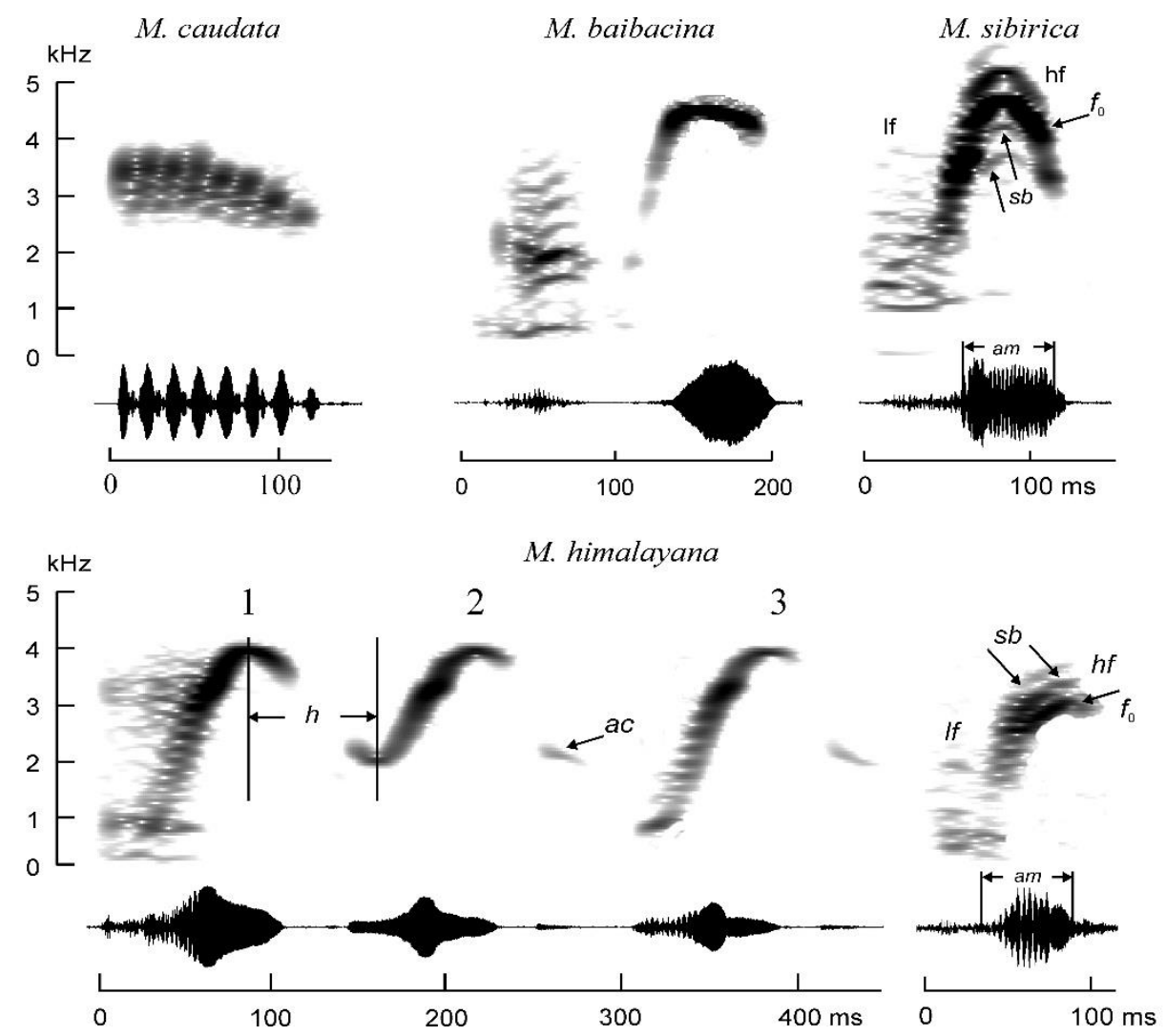

Fig. 2. Characteristics of the alarm call of the Himalayan marmot and its neighboring species. $l f-$ low frequency component, $h f$ - high-frequency component, $f_{0}$ - carrier frequency, $s b$ - side frequencies, $a m$ - amplitude modulation, $h$ - hiatus, $a c$ - additional component, 1-3 - serial numbers of sounds in the signal series of the Himalayan marmot.

The sound signal of the Himalayan marmot differs from the signal of other species of marmots of Eurasia, including neighboring, by the presence of a hiatus between the first two sounds and an additional component (Fig. 2) [10]. Hiatus can be of varying degrees (Fig. 2,3), which is probably a consequence of individual variability. 

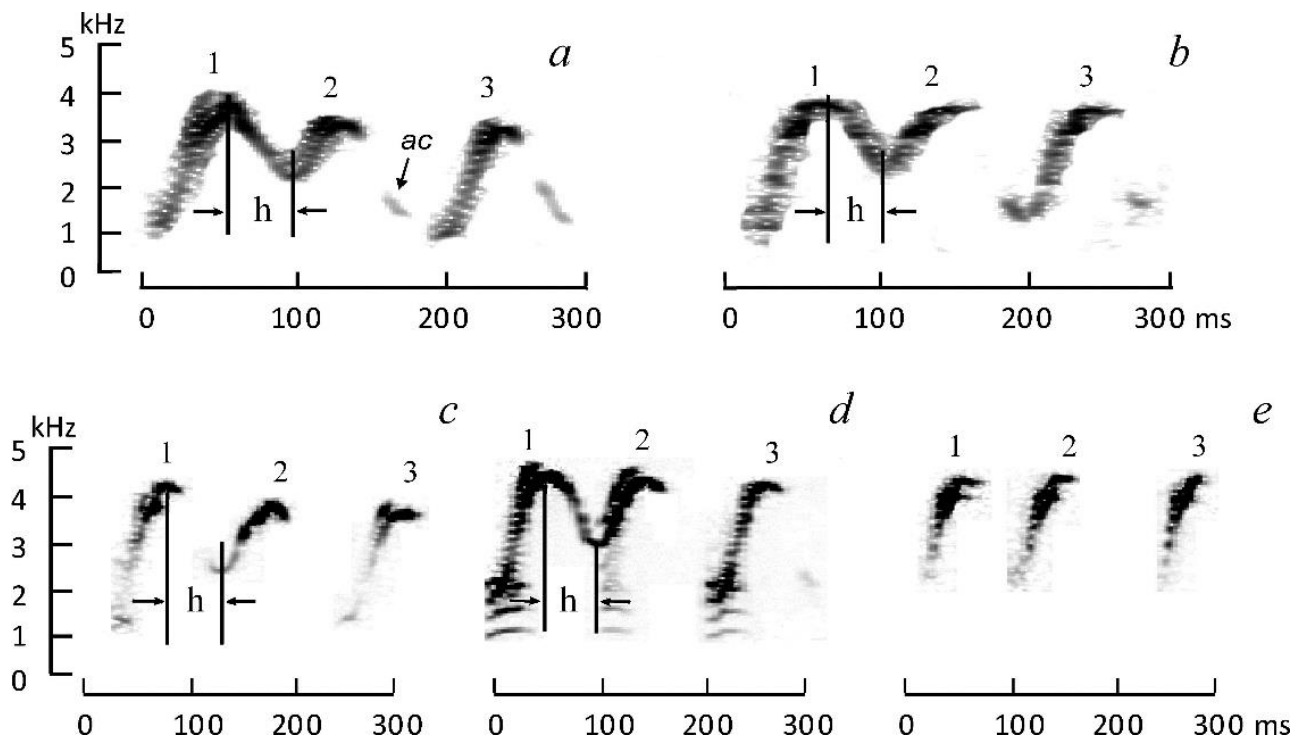

Fig. 3. Sonograms of the alarm call of the Himalayan marmot. Populations: $a$ - "Manaslu", $b-$ "Xining", $c, d-$ - Kunlun", $e$ - "Sarchu". 1-3 - the first 3 sounds in the signal series, $h$ - hiatus between the first and second sounds. In the "Sarchu" population $(e)$ hiatus is absent.

Comparing the sound signal of the Himalayan marmot with the signal of neighbors in the range, we find its similarity with the signal of the northern neighbor, the Mongolian marmot. A low-frequency component and amplitude modulation are regularly encountered both in the signal of the Himalayan marmot, as well as in the signal of the Mongolian marmot (Fig. 2).

Earlier [10], we carried out a cluster analysis of the sound signal of Eurasian marmots based on a complex of features, which confirmed the mutual similarity of the signal structure of two species of marmots - Himalayan and Mongolian (Fig. 4). Moreover, the mutual proximity of these species was confirmed by two independent groups of researchers at the level of nuclear and mitochondrial DNA [5, 18]. The dendrogram from the work of Steppan et al. [18] was compared with the dendrogram showing the distance of similarity of the sound signal features of Eurasian marmots (Fig. 4). In both dendrograms we see that the Himalayan and Mongolian marmots fall into the same cluster.

The proximity of the Himalayan and Mongolian marmots needs a special study in the future, as an example of the influence of landscape evolution on interspecific divergence. It can be assumed that the once one-whole space that unites the Tibetan Plateau with the Mongolian Plateau was inhabited by a common ancestor for both marmot species, which came from the northern mountain frame of the modern Mongolian Plateau. The aridization of the Tarim Basin, which began about 5 million years ago, separated the Mongolian Plateau from the Tibetan Plateau with deserts insurmountable for marmots, and led to the fragmentation of the metapopulation of a common ancestor. It became the cause of divergence, the consequences of which we observe now as the specificity of the Mongolian and Himalayan marmots. Our hypothesis is confirmed by the results of the historical geology research of Central Asia [16, 17].

In the context of the above, it is interesting to note that the nominal form of the blackcapped marmot M. camtschatica $c$., the northeastern neighbor of the Mongolian marmot in the Baikal region [19] inclines to the cluster M. himalayana - M. sibirica (Fig. 4), which of course is not an accidental coincidence and should also be the subject of a special study. 
(a)

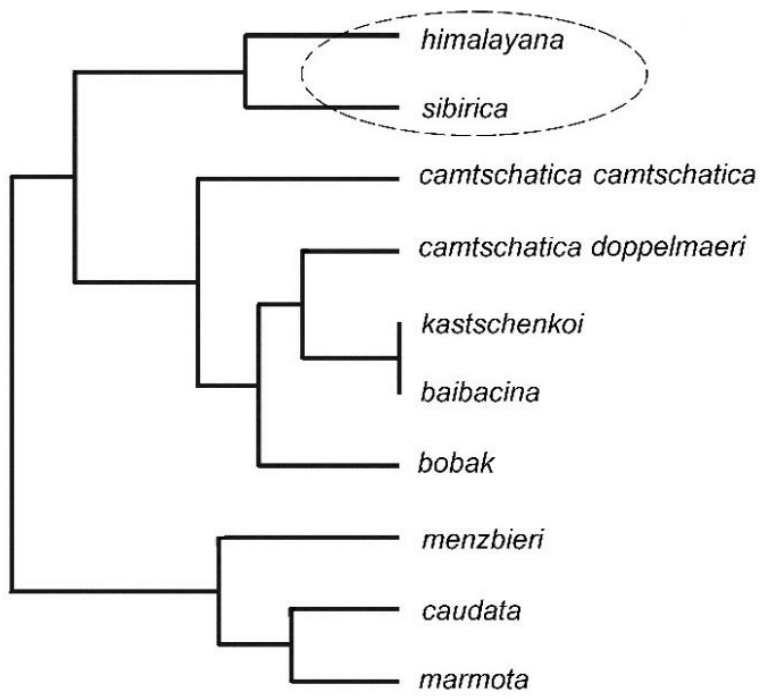

(b)

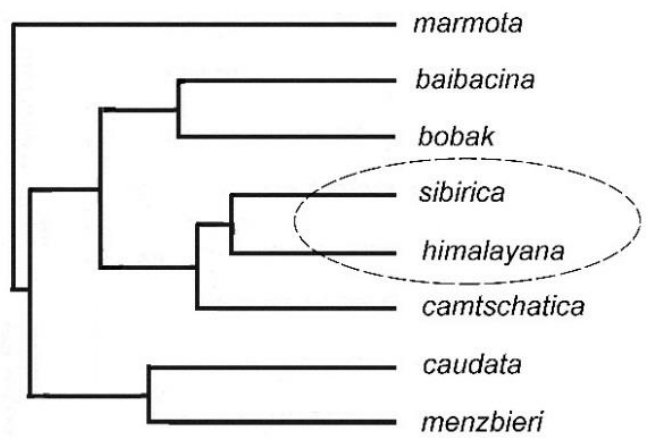

Fig. 4. Cluster diagrams of the similarity of Eurasian marmots: $a$ - alarm call (according to [10], as amended); $b$ - pooled nuclear and mitochondrial DNA data (according to [18], as amended).

As a preliminary result, we can conclude that the Himalayan marmot populations "Manaslu", "Xining" and "Kunlun" demonstrate the main species-specific features - a different degree of hiatus between the first two sounds and an additional sound (Fig. 3 : ad). At the same time, in the peripheral population "Sarchu" in the periphery southwest of the species range, in the westernmost region of the Himalayas, the signal lacks typical features for the species - there is no hiatus between the first two sounds, and there is no additional sound. Unfortunately, we have at our disposal the single sound signal record from the "Sarchu" population of the Himalayan marmot. Therefore, we cannot explain with certainty the reason for the unusual variability. Considering the peripheral position of the "Sarchu" population and its small size, it cannot be ruled out that the deviation of the sound signal from the species specificity is a consequence of gene drift, which was previously shown on the example of the steppe marmot [20]. We hope that future research will be able to confirm or deny this unexpected phenomenon of variability.

\section{Conclusion}

In conclusion, we would like to draw attention to one paradoxical fallacy in the literature. In various publications devoted to the fauna of Nepal, the Himalayan marmot is called 
"Bobak Marmot, Marmota bobak (Muller)", or in other words, the steppe marmot. As an example, we reproduce a fragment from Shrestha's [21:87] book "Mammals of Nepal" (Fig. 5).

\section{Bobak Marmot}

\section{Marmota bobak (Muller)}

The bobak marmot has body and limb pale tawny mixed with black on upper parts. The face and terminal third of tail are dark brown. Its belly fur is very scanty and buff in colour. The ears are small and rounded and thickly fringed with hairs on both surfaces. The tail is black tipped. This animal has head and body length about $60 \mathrm{~cm}$ and tail $15 \mathrm{~cm}$. It is reported from Annapurna Conservation Area, Sagarmatha, Shey-Phoksundo and Makalu Barun National Park. It is also reported rom Mustang district. It ranges from Palaearctic. Steppes of southern Russia and Kazakhstan, formerly west to Poland and Rumania but range now much reduced in west; mountains of central Asia from Altai to south of Himalayas; Tibet, Szechhuan and Sikkim. It inhabits Tibetan steppe biotope in rocky ridges. Usually found in colonies which hibernate in winter. Its altitudinal range is $3960-5500 \mathrm{~m}$.

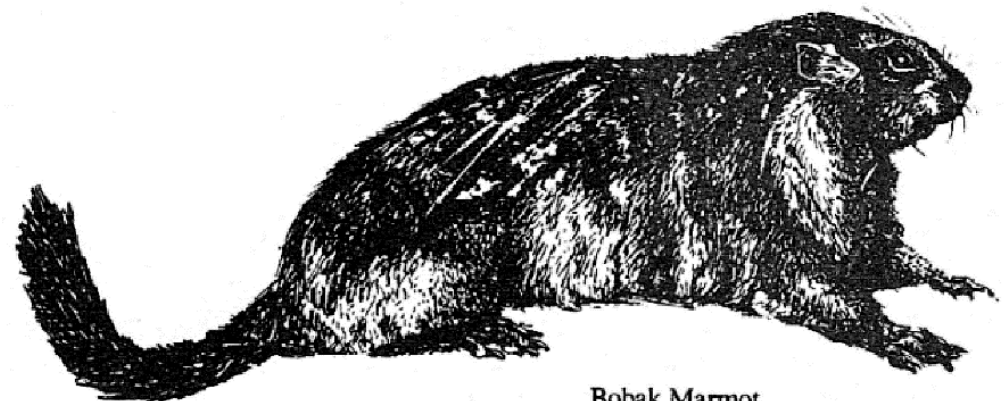

Fig. 5. Excerpt from the book "Mammals of Nepal" [21:87].

This unfortunate mistake has been represented in various publications for many years. Acoustic diagnostics and diagnostics using nuclear and mitochondrial DNA confirm the large distance between the Himalayan marmot and the steppe marmot (Fig. 4), which is not surprising: the range of the Himalayan marmot is separated by the vast area of the gray marmot range in the Tian Shan and Altai from the steppe marmot range (Fig. 1). The steppe marmot, the direct opposite of the Himalayan marmot, is the only plain species of the genus Marmota, inhabiting the hilly-ridged plains from Ukraine to Central Kazakhstan.

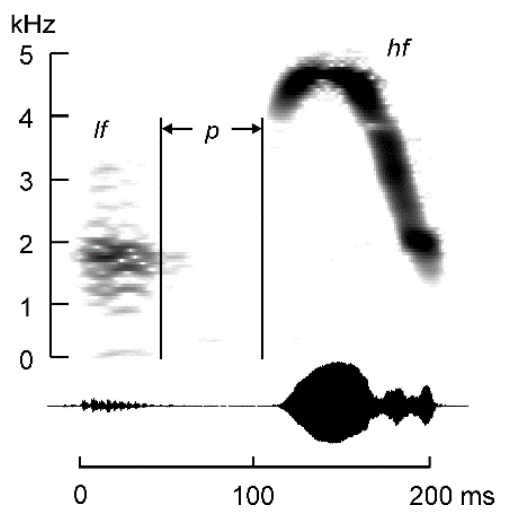

Fig. 6. Characteristics of the steppe marmot alarm call: $l f$ - low frequency component, $p$ - pause between components, $h f$ - high frequency component. 
At Fig. 6 we demonstrate the characteristics of a typical steppe marmot sound signal. Comparing with Fig. 2, we see absolute differences between the sound signals of the Himalayan and steppe marmots.

In our report, we wanted first of all to draw attention to the insular nature of the range of the Himalayan marmot. This giant continental "island" can become a promising model for studying the mechanisms of variability not only of the Himalayan marmot, but also of many other species of organisms under the conditions of dynamic geological processes, which have been actively discussed in the literature in recent years [16]. The projection of variability on the structure and history of the landscape creates favorable prerequisites for understanding the ecological and geographical factors of divergence as the basis for the process of speciation [22].

\section{References}

1. W. L. Sclater, Catalogue of Mammalia in the Indian Museum, Calcutta. Part II. Rodentia, Ungulata, Proboscidea, Hyracoidea, Carnivora, Cetacea, Sirenia, Marsupialia, Monotremata (Trust. Indian Mus., Calcutta, 1891)

2. I. M. Gromov, D. I. Bibikov, I. I. Kalabukhov, M. N. Meier, Fauna of the USSR. Mammals. T. III. Vyp.2. Terrestrial Sciurids (Marmotinae) (Nauka, Moscow, Leningrad, 1965) [rus.]

3. Wang Sibo, Yang Ganyun, Rodent Fauna of Xinjiang (Xinjiang People's Publishing House, Wolumuqi, 1983) [chin.]

4. R. S. Hoffmann, D. Lunde, J. MacKinnon, E. Wilson Don, W. C. Wozencraft, Guide to the Mammals of China. A.T. Smith, Yan Xie (eds.) (Princeton University Press, Princeton, 2010)

5. Jingyan Yan, Hongjian Chen, Gonghua Lin, Qian Li, Jiarui Chen, Wen Qin, Jianping Su, Tongzuo Zhang, PLOS ONE (2017)

6. A. A. Nikol'skii, V. Yu. Rumiantsev, Wang Chi, RUDN J. of Ecology and Life Safety, 1 (2014) [rus.]

7. A. A. Nikol'skii, N. A. Formozov, Rus. J. Zoology, 84, 12 (2005) [rus.]

8. N. I. Kriger, Loess, its characteristics and relation to geographical environment (Moscow: Nauka, 1965) [rus.]

9. A. A. Nikol'skii, E. A. Vanisova, R. Ramousse, Bull. mens. Soc. linn. Lyon, 88, 3-4 (2019) [fr.]

10. A. A. Nikol'skii, Rus. J. Zoology, 93, 8 (2014) [rus.]

11. A. A. Nikol'skii, V. M. Kotlyakov, D. T. Blumschtein, Doklady Biol. Sciences, 368, 6 (1999)

12. A. A. Nikol'skii, Wang Chi, RUDN J. of Ecology and Life Safety, 3 (2015) [rus.]

13. V. I. Kapitonov, Institute of Zoology, Academy of Sciences of the Kazakh SSR. Proceedings, 26 (1966) [rus.]

14. A. A. Nikol'skii, I. Yu. Yanina, M. V. Rutovskaya, N. A. Formozov, Rus. J. Zoology, 62, 8 (1983) [rus.]

15. S. Yu. Kapustina, E. A. Lyapunova, Ya. Adiya, O.V. Brandler, Doklady Biochemistry and Biophysics, 482, 6, (2018)

16. Yingying Sha, Zhengguo Shi, Xiaodong Liu, Zhisheng An. J. of Geophysical Research Atmospheres, 120, 10 (2015)

17. Jimin Sun, Tungsheng Liu, Science, 312, 5780 (2006) 
18. S. J. Steppan, G. J. Kenagy, Ch. Zawadzki, R. Robles, E. A. Lyapunova, R. S. Hoffmann, J. of Mammalogy, 92, 5 (2011)

19. M. A. Erbaeva, Rus. J. Theriology, 2, 1 (2003)

20. A. A. Nikol'skii, Biology Bulletin, 55, 6 (2008)

21. T. K. Shrestha, Mammals of Nepal (With Reference to those of India, Bangladesh, Bhutan and Pakistan) (R.K. Printers, Kathmandu, 1997)

22. E. Mayr, Animal Species and Evolution (Oxford Univ. Press, London, 1963) 